\title{
LÓGICAS DE JUSTICIA Y EMANCIPACIÓN: UNA LECTURA DE NANCY FRASER
}

\author{
LOGICS OF JUSTICE AND EMANCIPATION: A READING BY NANCY \\ FRASER \\ (D) Javier Fernández B. .* $^{*}$ \\ jfernandezb92@gmail.com \\ ${ }^{1}$ Universidad de Chile, Santiago de Chile, Chile
}

\begin{abstract}
*Correspondencia: Javier Fernández B. Email: jfernandezb92@gmail.com
\end{abstract}
Recibido: 13.08.21 | Aprobado: 08.09.21

\section{RESUMEN}

El presente trabajo es una lectura sobre el pensamiento de Nancy Fraser, basado principalmente en el texto "¿De la distribución al reconocimiento? Dilemas de la justicia en la era $<<$ postsocialista $>>$. En éste, sostenemos que es posible encontrar aportes significativos por parte de la pensadora norteamericana, toda vez que permitiría articular políticas que rebasen los meramente identitario y económico, posibilitando mixturas fundamentales para en una sociedad por venir. Se reflexiona en torno a cómo la propuesta de Fraser haría sentido con nuevos derroteros y darían cuenta de elementos en debate actualmente que construirían un nuevo orden de sentido desde la teoría política.

Palabras clave: Distribución, Reconocimiento, Nancy Fraser, Postsocialismo.

\begin{abstract}
This paper is a reading on Nancy Fraser's political thinking based mainly on the text From distribution to recognition? Dilemmas of justice in the $<<$ postsocialist $\rangle>$ age. We argue that it is possible to find significant contributions from the North American thinker that would allow for the articulation of policies that go beyond both identity politics and economic issues, enabling fundamental mixtures for a society to come. We reflect on how Fraser's proposal would make sense with new directions and how it would account for elements currently under debate that could set up a new framework of meaning from the field of political theory.

Keywords: Distribution, Recognition, Nancy Fraser, Postsocialism.
\end{abstract}




\section{INTRODUCCIÓN}

Desde hace un tiempo, la proliferación de las luchas sociales acaecidas en el mundo entero, que han cuestionado el estatus de democracia de los sistemas actualmente vigentes, ha traído a colación una serie de dificultades para el pensamiento contemporáneo, al momento que la viejas claves desde donde la teoría había operado han sido puestas en tela de juicio, principalmente por la capacidad que han tenido (o no) para poder analizar en su justa medida los cambios suscitados al alero de las crisis continuas del capitalismo contemporáneo.

No es extraño, en esa línea, que aquellos axiomas sostenidos fuertemente en no pocos documentos que aventuraban el fin de la historia, el triunfo del neoliberalismo y la caída de las "viejas luchas" hayan tenido un cuestionamiento no menor, dada principalmente no sólo las crisis económicas que trajeron nuevamente a la palestra aquel espectro de Marx (comentado profusamente por Derrida), sino que también, distintos cuestionamientos hacia el sistema en su conjunto de democracia que, tal y cómo se ha visto en el último tiempo, no habría bastado para dar cuenta de los sentires de una población que se vio cada vez más alejada de los frutos de aquel sistema.

Particularmente las sucesivas crisis de legitimidad del status quo que han estallado en diversas partes del mundo, erigieron un discurso crítico con el proyecto liberalizador mundial, toda vez que a las cifras macroeconómicas que enorgullecían a una parte no menor de la intelligentsia dominante chocaron de lleno con las formas de vida de una población que no sólo no daba abasto con sueldos, pensiones y acceso a servicios básicos, sino que también, con una multiplicidad de identidades que se habían visto postergadas por el Estado y la sociedad en su conjunto. A saber, mujeres, identidades LGBTIQ+, pueblos originarios o migrantes (por mencionar algunos) sacaron la voz para reclamar la incapacidad de la institucionalidad para encarar en lógicas de justicia sus demandas, a la vez que veían en su propia realidad -y la de sus cercanos- la no consideración de sus vidas.

Aun cuando dichas disputas aún siguen abiertas -considerando que la conflictividad ha mermado, pero no desaparecido-, establecen una serie de cuestiones necesarias de atender, dadas principalmente por cómo este fenómeno se entrecruza con una noción global de nuevas lógicas de emancipación que habrían erigido en un movimiento que no sólo empuja por reconocimiento en el espacio de la institucionalidad, sino que también, cómo se accede a los bienes básicos de la vida. Por tanto, no estaría lejos de aquella consigna instalada de "hasta que valga la pena vivir".

La filósofa Nancy Fraser ha abordado muy bien aquellas problemáticas, articulando con ello un discurso en torno a la justicia desde nuevas ópticas, en donde desde la Teoría Crítica, ha podido originar un cuestionamiento tanto a las nociones monolíticas, como aquellas que serían incapaces de atender ciertos elementos generales del sistema en cuestión. Específicamente, temas como el reconocimiento y la redistribución forman parte importante de su investigación, elemento que nos parece de sumo fundamental para poder empezar a entablar un diálogo que permita observar no sólo la eventual solución a estas problemáticas específicas, sino que también, la posibilidad de construir nuevas relaciones que logren establecer lógicas de vida para una -posible- nueva sociedad. 
Mencionado lo anterior, el presente trabajo pretenderá sostener un diálogo con la teórica Nancy Fraser y sus lógicas sobre la justicia desde ciertas claves de lectura, ensayando posibles interpretaciones a la vez que primeros acercamientos que apunten a generar reflexión sobre el momento que actualmente vivimos y cómo estos podrían ser elementos sustantivos para pensar una democracia que integre a todas las personas y modos de vida en su totalidad.

Para lograr nuestro fin, nos basaremos en el popular escrito " $¿ D e$ la distribución al reconocimiento? Dilemas de la justicia en la era <<postsocialista >>” (2000), ya que el mismo establece ciertos lineamientos del pensamiento de la teórica que articularían claves para afrontar los dilemas presentados. Sostendremos con ésta, que cualquier lógica que apunte a la emancipación no bastará simplemente su disputa en elementos identitarios, sino que debe originar en conjunto una lógica redistributiva, en donde -como se ha postulado- la transversalización sería la única vía posible de hallar una unificación de luchas a fin de establecerse, antes que como identidades separadas, como un pueblo.

El trabajo en cuestión se organizará, en un primer momento, en la exposición sucinta de los planteamientos de Fraser, y las distinciones que encontraría en una política Afirmativa y de Transformación, dejando en claro cómo, para ésta, sería la capacidad de Transformación la que debería imperar y, en ese sentido, estipular un derrotero emancipador.

En un segundo momento intentaremos articular el pensamiento de Fraser con ciertos/as teóricos/as quienes, por un lado, verían en la capacidad de unificación de luchas la posibilidad de apuntar a una eliminación en las lógicas de dominación; y por otro, la necesidad de avanzar en fórmulas que apunten a avanzar en la Democracia.

En un tercer y último elemento abordaremos las conclusiones de nuestro trabajo, intentando postular cómo cierta literatura daría cuenta de la necesidad de nuevas luchas identitarias que se entrecrucen con la redistribución que critique al sistema, y que al mismo tiempo establezca nuevas formas de vivir. Es cierto que aun cuando ciertos/as pensadores/as no coincidan en elementos estratégicos, sí es cierto que parecería haber una no despreciable producción que concuerda que los caminos recorridos en los últimos tiempos desde la caída de los denominados "socialismos reales" tampoco han sido los propicios para el buen desarrollo humano, y que sería urgente pensar otras formas de hacer las cosas, y pensar -al mismo tiempo- nuevas formas de democracia.

El presente trabajo está lejos de ser un análisis acucioso del pensamiento de Nancy Fraser, más bien, es una excusa (si se quiere) para debatir ciertas problemáticas contingentes en torno a la justicia y la democracia, toda vez que el momento político exige nuevas respuestas y reflexiones, a la vez de la necesaria generación de posibilidades para un nuevo mundo que supera (al parecer) viejas visiones.

\section{RECONOCIMIENTO, REDISTRIBUCIÓN Y LÓGICAS AMBIVALENTES}

Dice Fraser (2000) que, en la época actual, categorizada como "postsocialista", la lógica identitaria habría superado a las lógicas de clase, trasladando así el eje de gravedad desde la redistribución económica, hacia las luchas en pos del reconocimiento identitario 
cultural. No obstante, señala la norteamericana, una política emancipatoria necesita de ambas miradas: la redistribución y el reconocimiento como dimensiones inseparables.

Por un lado, las demandas de tipo económica estarían relacionadas en la estructura económica-política, donde cuestiones como las diferencias de clase, o ámbitos de ingresos cumplen una labor central en dicha dimensión. Por otro lado, las de reconocimiento, estarían marcadas por las de tipo identitario cultural, en donde su identificación y disputa se daría por la superación de visiones que anularían otras formas de vida o existencias a las hegemónicas, estableciendo modos de vida canónicas desde el cual operar.

En ese sentido.

Las reivindicaciones de reconocimiento a menudo se convierten en apelaciones, cuando no en realizaciones prácticas, a la supuesta especificidad de cierto grupo y, por tanto, afirman el valor de dicha especificidad. En este sentido, tienden a promover la diferenciación de grupo. Por el contrario, las reivindicaciones redistributivas a menudo apelan a la abolición del orden económico que sostiene la especificidad de grupo (Fraser, 2000; p. 33)

De acuerdo con Lobatón (2018), la categoría de "redistribución" -utilizada por Fraser- tendría un origen Liberal, dado que la misma estaría anclada en la concepción de justicia redistributiva y justicia social, estableciendo elementos que la misma autora contemplaría dentro de su análisis pero que, a la vez, superaría en el entendido de que la misma instituiría una crítica a la concepción Liberal de la redistribución, estableciéndola como insuficiente en las luchas por la emancipación. En la misma línea, dice el autor, las lógicas de reconocimiento "proviene de una tradición filosófica hegeliana particularmente desde el fenómeno de la consciencia, sus defensores son pensadores neohegelianos, tales como Charles Taylor y Axel Honneth". (Lobatón, 2018; p. 212).

Para Fraser, tanto las disputas por la distribución, como las por el reconocimiento por sí solas serían insuficientes, dadas su incapacidad de observar el problema en su conjunto y la diversidad de luchas que se suscitarían en el mismo tiempo. Con ello, la pensadora cuestionaría que

La gramática del reconocimiento sea la forma normativa hegemónica de la lucha política y objeta los efectos de esa gramática en la dinámica del conflicto, ya que tal teoría puede vaciar parte de las reivindicaciones de los movimientos sociales y poner de espaldas la teoría crítica frente a cuestiones distributivas (Barbosa, 2019; p.31).

De acuerdo con la teórica "lejos de ocupar dos esferas separadas herméticamente, la injusticia económica y la injusticia cultural se encuentran habitualmente imbricadas hasta el punto de reforzarse dialécticamente la una a la otra" (Fraser, 2000; p.30).

En ese sentido, la estadounidense irá un paso más allá aseverando que esta imbricación marcará algunas identidades cruzadas tanto por lógicas identitarias como económicas en, por ejemplo, cuestiones como el género o la raza. Éstas no sólo encontrarían discriminaciones de tipo colonial-eurocéntrico (en lo referente a la raza) o lo heterosexista (en el caso del género) en lo relativo a denostaciones de tipo cultural subjetivo, sino que también, en el plano económico también estarán signadas por la división sexual o racial del trabajo que los designará en labores "menores" para la sociedad 
capitalista, demostrando así que la opresión sería más compleja que una mera cualidad. Ahora bien, Fraser denominará esto como "Comunidades Bivalentes", cruzadas por distintas opresiones que, en sentido último, entrarán en conflicto debido a que, en las lógicas Liberales, lo redistributivo establecería un reconocimiento generalizado e integrado en la comunidad, a diferencia de las identidades que pugnarían por la diferenciación. ¿Qué se debería privilegiar? ¿hay una más importante que la otra?

Ante la disyuntiva, Fraser consignará la existencia de una dualidad fundamental en la resolución por parte de la problemática: un tipo de política afirmativa y otro de tipo transformadora. En palabras de la pensadora, ésta entiende

Por soluciones afirmativas a la injusticia que tratan de corregir los efectos injustos del orden social sin alterar el sistema subyacente que los genera. En cambio, por soluciones transformadoras entiendo las soluciones que aspiran a corregir los efectos injustos precisamente reestructurando el sistema subyacente que los genera (Fraser, 2000; p.48).

De acuerdo con este planteamiento -explica la misma autora-, los espacios redistributivos clásicos del Estado de Bienestar Liberal estarán signados por una política afirmativa, toda vez que los mismos no cuestionarán en ningún momento las relaciones de clase y sus conflictos en la sociedad, contentándose con una lógica distributiva que, muchas veces, siga poniendo en pugna a las clases oprimidas y que las mismas propenderán a "beneficios" en desmedro de otros. Por otro lado, esta misma política afirmativa en la lógica identitaria, establecerá mejoras en cuestiones de género, derivando a puestos empresariales o mejoras para las mujeres o las diversidades sexuales sin poner en tela de juicio las lógicas binarias existentes. Como respuesta a esto, Fraser postula que las lógicas transformadoras encontrarían en lo redistributivo al Socialismo y en las identidades a la Deconstrucción. Ambas, estarían entrecruzadas y se encontrarían mutuamente como estrategia de liberación.

Ante las Comunidades ambivalentes, la capacidad de poder encontrar una imbricación entre Socialismo y Deconstrucción como política transformadora sería la opción para generar nuevos planos de disputas y la construcción de nuevas lógicas para la sociedad.

Ahora bien, habiendo repasado brevemente los planteamientos de la autora ¿cómo es posible articular nuevas formas de pensamiento para una nueva sociedad en disputa en la actualidad?

\section{EMANCIPACIÓN Y CONSTRUCCIÓN DE NUEVAS POSIBILIDADES}

Como mencionamos en un comienzo, las disputas en la actualidad han logrado una proliferación, dado principalmente por la capacidad de encontrarse mutuamente, así como también, de poder ir generando cada vez nuevas demandas en el entendido de la emergencia continua de identidades y colectivos diversos.

Si bien sería errado a nuestro juicio sostener la superación de luchas asentadas como lo son las del movimiento obrero, no sería exagerado sí sostener que disputas acaecidas en el último tiempo como las feministas o de reconocimiento étnico ha supuesto para 
éstas una complejización, dado que muchas veces hallan puntos de conexión importantes alegando contra el Estado y el déficit de acceso a los beneficios del progreso.

En dicho sentido, no es de extrañar la emergencia de movimientos reivindicadores en el plano de las identidades en el último tiempo, siendo tal vez uno de los más mediáticos, el referente a un racismo institucionalizado en distintos países del centro capitalista. A la par que se comprendió la discriminación estructural en base al color de piel, se entendió ésta también desde un plano transversal, demostrando que, lejos de un reclamo eminentemente económico, todas las luchas se encontraron, articulando una transversalidad que rebasaba con creces lo meramente económico.

Esta constatación daría pie a cómo, desde Fraser, la suerte de dualidad representación redistribución apostaría a ser, por lejos de una dicotomía insuperable, un hecho constatable pero que debía encontrarse en lógicas transformadoras de sí quería generar un camino viable a su superación. No obstante, sería arriesgado sostener que en la pluralidad de subjetividades que significan los movimientos sociales esto sería sostenido con vehemencia. Simplemente hacemos notar que existiría un germen importante nacido desde un tiempo a esta parte que pudo ser constatado durante las distintas movilizaciones que han tomado figuras o símbolos de pueblos originarios o grupos subalternos marginalizados como símbolo de resistencia, aun cuando no se perteneciera propiamente tal grupo en cuestión.

Ejemplo de esto fue el apoyo que concitaron movimientos como "Black Lives Matter" más allá de la identificación por una cuestión étnica.

Las demandas de Fraser por la generación de una imbricación de las luchas es posible de encontrar -a nuestro entender- en las demandas que hicieran otras teóricas el último tiempo. Chantal Mouffe (2016) -en conversación con Iñigo Errejón-, ha establecido la necesidad de que las disputas surgidas en el último tiempo se unifiquen, precisamente, superando una suerte de esencialismo basal desde el que se habrían formado una nueva capacidad de reconocerse en sus luchas y en sus intereses emancipatorios en donde, comprendiendo que las lógicas de opresión no serían todas iguales, sí necesitan establecerse desde una común unidad, es decir transformase en Pueblo. Esta idea, claramente chocaría de lleno con quienes, por lejos del grupo, apelan al individuo generando así una diferenciación importante, en tanto -con más o menos cercanías- Mouffe parecería encontrarse con Fraser en la necesidad de transversalización de las demandas.

Tanto para Mouffe como para Fraser, sería necesario hallar elementos constitutivos de la democracia que permitan crear instancias de profundización que consideren la pluralidad de demandas y que permitan a las y los sujetos hacerse con la capacidad de decisión no sólo de un reconocimiento institucional, sino que también, de la capacidad de romper con las lógicas de opresión económica. Esto no es baladí cuando la misma Mouffe (1998; 2016) establecerá las lógicas de radicalización democrática en la necesaria superación de nociones eminentemente liberales por ser insuficientes, y que no permitirían precisamente una democracia efectiva. Éstas serán conclusiones medianamente similares a las que apuntará Fraser (2000), señalando que sería el Estado de Bienestar Liberal que, aun cuando lleno de buenas intenciones, sea incapaz de dar una 
solución transformadora a las demandas al no cuestionar sus mismas formas de funcionamiento.

En ese sentido, una política efectiva para Fraser requería ciertas condiciones basales para una real consideración democrática, lo que ha denominado como "paridad de participación". Se entendería por ésta

La condición de ser un igual, de estar a la par con los demás, de estar en pie de igualdad. El requisito moral es que se garantice a los miembros de la sociedad la posibilidad de la paridad, si optan por participar en una determinada actividad o interacción y cuando lo hagan. No se exige que todo el mundo participe en tal actividad (Lobatón, 2018; p.216).

Siguiendo a la misma autora, habrían condiciones objetivas que permitirían esta paridad, las cuales se entenderían como:

En primer lugar, la distribución de los recursos materiales debe hacerse de manera que garantice la independencia y la 'voz' de todos los participantes. Llamaré a esta la condición objetiva de la paridad. Excluye las formas y niveles de dependencia económica y de desigualdad que impiden la paridad de participación. En consecuencia, quedan excluidos los acuerdos sociales que institucionalicen la privación, la explotación y las grandes disparidades de riqueza, ingresos y tiempo de ocio, que niegan a algunas personas los medios y las oportunidades de interactuar con los demás como iguales (Fraser, 2006; p.42, citado en Lobatón, 2018)

Esta norma paritaria, que se encontraría por sobre la mera lógica de justicia, en el entendido de una mera ejecución, sería la conditio sine qua non de la democracia y las lógicas de justicia, toda vez que la misma contemplaría formas de consideración de las y los sujetos en la misma administración de sus vidas, sin que por ello signifique una anulación de sus propias identidades. A nuestro juicio, dichas premisas establecerían semejanzas con la misma Mouffe debido a nociones que apuntarían a una radicalización de la democracia, principalmente, en el entendido que se concebiría que las disputas como un corpus unificado -sin por ello perder las independencia- podría establecer un mecanismo de lucha valedero para el momento político que vivimos.

Sin querer forzar nuestro argumento y las lógicas de equivalencia que hemos expuesto con otra pensadora y nuestro objeto argumental inicial, lo que queremos señalar acá es que la posibilidad de comprender que no bastaría lo meramente identitario o redistributivo, sino que una política transformadora -siguiendo a la norteamericanapermitirá construir alternativa como un elemento estratégico importante. Para ello, debe establecer elementos constitutivos de su política desde un ámbito paritario dónde los modos de vivir se encuentren y disputen reconocimiento y redistribución, a fin de cuentas -según nosotros- la generación de un Pueblo que, con sus matices más y matices menos, también hallaría puntos de encuentro con otros postulados, como los de la misma Chantal Mouffe.

A nuestro juicio, la política transformadora requeriría para su consecución entenderse, antes que como un todo atomizado, como un Pueblo plural pero que se concreta en una lógica dialéctica con otros proyectos. Aun cuando la unificación de 
demandas de modos de vida y redistribución deben estar en una consideración igualitaria con distintas estrategias políticas, no es menos cierto que no es posible de aseverar que estas se hallarán por forma natural, por lo que la capacidad de identificar sus mismas estrategias en puntos en común será un elemento fundamental que, a nuestro juicio, debe existir en una política transformadora, tal y como señala Fraser. Para ello, las condiciones de paridad de participación que anuncia la filósofa norteamericana parecen ser un buen elemento procedimental para un nuevo tipo de democracia (y su radicalización). Sin embargo, no es menos cierto que la generación de un Pueblo plural requeriría observar estas diferencias y unificarse en torno a ellas ¿es que acaso quienes demandan redistribución, por mencionar un caso, y adscriben a comportamientos contrarios a lo que hablamos no son parte de los sectores explotados? La cita que mencionamos anteriormente creemos que lo deja bastante claro, excluyendo del arreglo institucional todo aquel que prive de su existencia modos de vida distintos o nieguen la redistribución. Esto parecería acorde a un nuevo tipo de política democrática, aun cuando, claro está, sería necesario seguir dilucidando e hilando fino en los procedimientos de exclusión e integración en las lógicas de funcionamiento.

Ahora bien, no obstante, los puntos de encuentro que a nuestro entender se presentan en las dos pensadoras mencionadas, no es menos cierto que Fraser (2006) establecería que los derroteros para llegar a dicha constitución democrática obligarían el debate y consensos -si se quiere- sobre la consideración o no de ciertas exclusiones. Mouffe (2016), por otro lado, es bastante reacia a las consideraciones consensuales. Como ha dicho la belga en múltiples ocasiones, la posibilidad de establecer el consenso como fin último del debate es ciertamente un error en la radicalización democrática, principalmente por el proyecto político defendido por ésta obligaría a la consideración siempre de alternativas y elementos no cerrados a priori, en donde cualquier forma de acuerdo estaría siempre sujeto a deliberación y el entendimiento que el consenso sería en sí mismo una quimera. Por tanto, en el arreglo basal, consideramos, debería establecerse siempre en una lógica abierta, dispuesta a la crítica y el cambio, no obstante, debe crearse a fin de ser válido como funcionamiento social en un tiempo prudente.

Dicha política transformadora como elemento estratégico que apunta a la generación de un Pueblo es, según nosotros, uno de los elementos importantes para consignarse un nuevo tipo de política en el mundo por venir. La creación de elementos que profundicen la democracia encontraría no sólo factores participativos en la gestión de la vida, sino que también, apuntaría a espacios dónde todas las vidas tengan cabida.

Desde el punto de vista de la justicia, dichos principios permiten establecer marcos más plurales, a la vez que obligarían a reconceptualizar no sólo qué entenderíamos por ésta, sino que también, cómo se crearían en una lógica de democracia y cómo, posiblemente, serían estos elementos redistributivos y de reconocimiento, los fundamentos centrales para que pueda darse de una manera efectiva.

No es nuevo, como hemos venido señalando, las críticas al Estado contemporáneo y el soslayo de una responsabilidad para con la población, en donde en muchos sectores la capacidad de redistribución de recursos no alcanzaría siquiera a las lógicas de Bienestar Liberal de las que habla Fraser. 
Ante ello, cierta literatura económica ha hecho hincapié en la necesidad de generar una redistribución más equitativa a fin de construir elementos más democráticos en la sociedad. Particularmente Acemoglu y Robinson (2019), desde una lógica liberal igualitaria, han propuesto la urgencia de que una redistribución de los recursos sería la condición de posibilidad de la estabilidad de los Estados, toda vez que los mismos, de no realizarla, crearían un caldo de cultivo que estallaría en expresiones violentas. Más allá de lo cierto o no de su análisis, las lógicas instrumentales de su análisis consignan puntos de desacuerdo con lo que hemos venido exponiendo: no se trataría simplemente desde una racionalidad instrumental la redistribución, se trataría al final del día, de elementos éticos de funcionamiento en donde dichos economistas, aun cuando bien intencionados, operarían desde una lógica afirmativa más que de una transformadora. Esto, ya que "Mientras las soluciones afirmativas pueden producir el efecto perverso de promover la diferenciación de clase, las soluciones transformadoras tienden a desdibujarla" (Fraser, 2000; p.54)

Mencionamos a estos autores porque dichos planteamientos se encuentran de manera fuerte en los debates de las disciplinas científico-sociales, principalmente porque sus postulados -se propone- serían elementos centrales para construir nuevas observaciones para un mundo por venir. No obstante, siguiendo a Fraser, sería errado sostener que éste fuera el camino para seguir en tanto, dice la autora, sería necesario avanzar no sólo en condiciones que se limiten a reconocer o a redistribuir, sino poner entre dicho las lógicas de acumulación del capital y, con ello, el funcionamiento del sistema mismo.

El pensar desde este sentido obligaría ya no a ver elementos redistributivos o de reconocimiento como mero procedimiento o cumplimiento con estándares básicos, sino ir un paso más allá a cuestionar el cómo se opera en la sociedad, sus factores educativos, económicos, judiciales y políticos, dado que los mismos se encontrarían en entredicho y obligarían a repensarse, tal y cómo la sociedad ha venido demandando desde el último tiempo. Sin embargo, y aun cuando muchos de esos lineamientos han encontrado eco en la ciudadanía no es menos cierto que obligan a repensar la forma en que éstos llegarían a puerto, dado que el cuestionamiento a la institucionalidad choca a la vez con sus demandas de justicia institucionalizada, y cómo se debería proceder en una lógica de representación.

Aun cuando los planteamientos de la autora que tomamos para reflexionar sobre estas lógicas exceden lo enunciado por ella, no es menos cierto que hay luces que nos permitirían aventurar -como ya hemos señalado- la necesidad de auto reconocerse en una pluralidad de demandas, y que tanto lo redistributivo como lo identitario deben encontrarse a fin de generar los elementos que propendan hacia políticas emancipatorias. Con ello, para Fraser, una preocupación económica que apunte a una redistribución transformadora "puede promover la solidaridad, contribuyendo a combatir algunas formas de reconocimiento inadecuado" (Fraser, 2000; p. 55)

Un planteamiento interesante en este sentido sería el establecido por Balibar (2012) para quien, lejos de prescindir de los elementos democráticos e institucionales, sería perentorio apuntar hacia su profundización, en lo que ha denominado como la "democratización de la democracia". Con ello, no se trataría de operar con una lógica 
excluyente, sino que incluyente que establezca marcos participativos de gestión no sólo como meros accountabilities, sino que de incidencia propiamente tal, cuestión que, según nosotros encontraría amplios puntos de convergencia con las propuestas de Fraser, en tanto serían los elementos democráticos los que permitirían esta política Transformadora.

Por tanto, apuntar a la dicotomía redistribución-reconocimiento como algo real es básico, pero esas comunidades ambivalentes deberán comprender la necesidad de que sus luchas se interconecten con las luchas de muchas otras subjetividades que, aun cuando no sufrientes de las mismas opresiones, encuentran desde la disrupción su emergencia -si es que su objetivo es la victoria-. Por tanto, no sería desde una lógica esencialista, sino desde la pluralidad del Pueblo, la capacidad misma para encontrar nuevas formas de construir un nuevo sistema democrático en la gestión social.

\section{CONCLUSIONES}

Lo que intentamos hacer acá fue un ensayo de lectura sobre una autora sumamente contingente que a la vez que debate sobre elementos redistributivos, ya asentados en la política crítica, ha traído elementos a la palestra, deconstruyendo viejas lógicas de sentido sobre el devenir de la comunidad en su conjunto.

En esa línea -como mencionamos al comienzo-, sin querer ser un examen acucioso de dicha pensadora, sí intentamos generar ciertas reflexiones sobre la democracia y la justicia, intentado consignar algunos lineamientos en torno a lo que Fraser consideraría una política transformadora.

En primer lugar, como se han visto en las movilizaciones del último tiempo, a las demandas por mayor igualdad económica irrumpe una demanda por una consideración de distintos modos/identidades de vida en la sociedad, reivindicando no ser mirada/o en menos. Por el contrario, se cuenta con una dignidad intrínseca y se requiere reconocimiento, pero a la vez, también una consideración de las discriminaciones económicas que se sufre debido a su identidad. Esta lógica, denominada como de Comunidades Ambivalentes por Fraser, están en el centro del debate del último tiempo, dado principalmente por si se debiese considerar la lógica identitaria o redistributiva como central. Lejos de aquel maniqueísmo, Fraser respondería: las dos al mismo tiempo. Sería necesario, entonces, crear nuevas formas de demandas que vayan hacia este objetivo.

En segundo lugar, para lograr esto sería necesario establecer elementos procedimentales que consideren estas formas de vida y, para ello, deben generarse la consideración de mecanismos paritarios para su consecución. No obstante, como ha señalado Mouffe, aun cuando conforme con la crítica de Fraser, sí es necesario tener en cuenta: primero, que las demandas sociales no se encuentran en el aire, y sólo la consideración de todas ellas en un mismo conjunto (el Pueblo y su necesidad de creación), puede permitir la victoria. No significaría en ningún caso la subsunción de una demanda por otra, sino entenderla en su pluralidad. Segundo, la necesidad de comprender que aun cuando la creación de mecanismos de funcionamiento establezca ciertos acuerdos, estos estarían por lejos de agotar el debate. Sería perentorio su profundización y reactualización constante si se quisiera llegar a algo realmente democrático. Aun cuando la profundización de un debate entre Mouffe y Fraser serían motivo de otro escrito, si nos pareció 
importante mencionarlo dado que éste podría permitir encontrar ciertos complementos necesarios para una política transformadora en los entendidos que nos plantea la estadounidense.

En tercer y último lugar, y lo que nos parece central, es que cualquier disputa económica o identitaria, para su victoria debe plantearse en términos radicales, en lo que por ello entendemos que sería el cuestionamiento continuo al sistema que lo ha creado. Aventuramos de manera adelantada de que muchas de las demandas actuales corren el serio peligro de avanzar desde una ahistoricidad idealista, que lejos de propender a una construcción material objetiva de sus contingencias, estaría armada desde la volatilidad que significaría la coyuntura y no cómo estas han sido luchas de años que deben encontrar una resolución en la plena crítica de un sistema en su conjunto, unificadas y no como mera alianza estratégica que una vez alcanzada la victoria se separe. En ese sentido, la creación de Pueblo requeriría superar discrepancias legítimas y apuntar hacia quienes efectivamente consideramos que deben ser beneficiados/as con dicha política.

Creemos que Fraser establece elementos importantes en tomar en consideración para este debate donde elementos en tensión no deben separarse, como por ejemplo clasegénero o clase-raza, llevando a pensar, por ejemplo, en las mismas especificidades de cada territorio.

Con ello, una política que pretenda ser verdaderamente transformadora no debería soslayar dichas premisas y considerarlas a fin de erigir elementos necesarios para establecer marcos reales y democráticos de vida.

El pensar una nueva sociedad requiere, a nuestro juicio, obligatoriamente pasar por estas reflexiones, en el entendido que un nuevo marco jurídico-político (que es la discusión que actualmente vivimos), obliga a pensarse nuevamente como comunidad histórica e imaginada y reflexionar sobre los elementos de unidad y diferencia, a fin de crear instituciones que propendan hacia la pluralidad y no hacia la homogeneidad. En ese sentido creemos, las instituciones podrían tomar un nuevo cuño, no sólo religitimándose, sino que tal vez, derivando de una manera real y efectiva hacia la consideración de todas las vidas y creando así instancias para que la vida "merezca ser vivida".

Claramente el debate está lejos de agotarse, pero como tratamos de aportar acá en estas reflexiones, existirían elementos para generar nuevas formas de pensamiento y organización, que sin duda pueden ser un aporte para los tiempos venideros.

\section{REFERENCIAS BIBLIOGRÁFICAS}

Acemoglu, D., \& Robinson, J. (2019). El pasillo estrecho: Estados, sociedades y cómo alcanzar la libertad. Deusto.

Balibar, É. (2012). Ciudadanía. Adriana Hidalgo.

Barbosa, S. (2019). Axel Honneth y Nancy Fraser, una Teoría Crítica de la sociedad capitalista para la contextualización de las luchas del presente. Ágora UNLaR, 4(9), $30-42$.

Errejón, I., \& Mouffe, C. (2016). Construir pueblo. Hegemonía y radicalización de la democracia. Icaria. 
Fraser, N. (2000). ¿De la redistribución al reconocimiento? Dilemas de la justicia en la era $<<$ postsocialista $>>$. En N. L. Review. Akal.

Fraser, N. (2006). La justicia social en la era de la política de la identidad: Redistribución, reconocimiento y participación. En A. Honneth, \& N. Fraser, ¿'Redistribución o reconocimiento? un debate filosófico-político (págs. 13-88). Morata.

Lobatón, R. (2018). Redistribución, reconocimiento y participación: dimensiones de la justicia social desde Nancy Fraser y Axel Honneth. En D. Ferrara, Políticas educativas y su impacto en las comunidades: Investigación en educación para la justicia social (págs. 209-227). UCM.

Mouffe, C. (1998). El retorno de lo político. Paidós.

Mouffe, C. (2016). La paradoja democrática. Guedisa.

\section{CITAR COMO:}

Fernández B., J. (2021). Lógicas de justicia y emancipación: Una lectura de Nancy Fraser. Puriq, 3(4), 610_ 621. https://doi.org/10.37073/puriq.3.4.241 